never be healthy, and in this as in other matters both the physiology and psychology of the community differs but little from that of the individual.

The Committee habit is something that has always affected certain persons just as the drug habit or the alcoholic habit affects others. It is not a new disease. Dickens says of it, "They threw themselves into committees in the most impassioned manner, and collected subscriptions with a vehemence quite extraordinary. They took a multitude of titles. They were the Women of England, the Daughters of Britain, the Sisters of all the Cardinal Virtues separately, the Females of America, the ladies of a hundred denominations. It made our heads ache to think, on the whole, what feverish lives they must lead." In these days Mrs. Jellyby and Mrs. Pardiggle have largely turned their attention from the souls to the bodies of their fellow-citizens, and the result is the amazing outburst of voluntary organizations which flood our desks with unwanted stationery. The number of societies, councils, and committees now competing with each other to promote the welfare of infants, to take only one instance, is either comic or scandalous according to our point of view. The waste of effort and especially the waste of money involved is pitiable.

Some attempt has been made to co-ordinate these agencies, but it was specially stated that this was to be done "without interfering with their individuality." What a timorous policy! Surely it would be better to have one organization and have it really organized with a properlythought-out policy?

What is even more serious is the power such well-intentioned organizations give to the fardist and the sentimentalist, with its consequent misdirection of policy.

We can see now that the money spent in the last twenty years on the treatment of tuberculosis would re-house the population and abolish almost every slum in our cities. It would make the people's homes their sanatorium-the only permanently effective one.

We are now spending some millions annually in the treatment of venereal diseases on lines which are questioned by at least half the medical profession, and we are about to introduce one milk for the rich and another for the poor.

For any craze that becomes fashionable it is now always possible to collect a few uneducated members of Parliament and a lady of title to form a "National Council" for its promotion.
It is difficult for medical officers and others concerned with the real administration of the public health to resist influences of this description, but while I expect the majority of those present to disagree with me as to some or all of the instances I have chosen as representing mistaken policies, I think we can agree that we who claim to be experts should not take our policy ready-made from any lay body however distinguished. That it is our duty not only to arouse public opinion to its own needs but also to restrain and guide it into paths which we are quite certain will lead to a higher standard of civilization and happier if not longer lives.

\section{DEFECTIVE DIET AS A CONTRIBUTARY CAUSE OF CERTAIN COMPLAINTS IN CHILDREN.}

BY

A. D. Symons, M.D., M.R.C.S., D.P.H., Assistant Medical Officer, County of Salop.

There are many people who believe that if we exclude certain specific microm and macroorganisms, the causation of all other ills of the human fiesh can in large measure be attributed to dietetic errors, such errors including overfeeding, underfeeding and wrong feeding. No doubt, instinct, reason, and past experience should, but does not, guide us to that which is right and proper, but that path is difficult and narrow, and more often with the feeling of "Let us eat, drink, and be merry," etc., we choose the easier, less restricted path and eventually suffer for our ignorance, indiscretion or indifference as the case may be.

I want to consider a few common complaints met with in school children, the direct or indirect causation of which may wholly or partly be attributed to dietetic errors, and of these errors, the chief, especially in elementary school children, is due to an unbalanced dietary with a large excess of carbohydrate foodstuffs.

Carbohydrate foods are relatively cheap, children like bread, potatoes, jam, sugar, sweets, pastry and cakes, and consume far more than is needed for the generation of heat and energy or the maintenance and repair of the tissues. It is this excess amount which either overtaxes the digestive organs, or cannot be dealt with, which is incompletely combusted and whose bye-products cause trouble in many ways, by lowering tissue tone or body resistance so that organisms can enter and play their part. 
We are rather too apt to assign certain diseases to a specific micro-organism, as much as to say that this particular organism was floating about, happened to land on such and such an individual and caused his disease.

Ought we not more often to go a little further back and consider the soil?. Would that organism fourish, thrive and multiply if the medium on which it finds itself is an adverse one? The antibody or immunity mechanism is in delicate adjustment with biochemical conditions in the body generally, and it is when these biochemical conditions are upset or out of order that the inmunity mechanism may be thrown out of gear or be functioning only feebly, and thus give a poor resistance to foreign antigens.

Seed will grow in suitable soil when other factors are favourable and the science of bacteriology has shown us that an optimum medium is necessary for the active growth of certain bacterial flora, the relative acidity or hydrogen ion concentration, and sugar content being of considerable importance. In what ways, then, is an excessive amount of carbohydrate food likely to interfere with normal healthy processes?

The metabolism of carbohydrate is essentially an $\delta$ xidation process, the complete combustion producing carbon dioxide and water, but when the body is unable to deal with large amounts, there is a preponderance of intermediate breakdown substances in the forms of organic acids which accumulate, are absorbed, and may be excreted as such. It is these acids which are harmful.

Now I think that one may consider three ways by which excessive ingestion of carbohydrate may derange metabolism and be a potential factor in the causation of ill-health.

Firstly.-Excess of carbohydrate upsets the proper balance which is so necessary in a diet conducive to good health. McCarrison ${ }^{1}$ has pointed out that " a diet that is unbalanced, and which contains a deficiency of suitable proteins, a deficiency of vitamines and an excess of carbohydrates leads to changes in the intestinal nucosa."

The resultant stasis from these changes in the intestinal mucosa leads to constipation and fermentation of the dammed-back carbohydrates, the impoverished epithelium becoming permeable so that acid produets of incomplete combustion bring about a state of auto-intoxication, with a consequent drain on the alkaline resources of the body.

Secondly.-The presence and circulation of these organic acid intermediary products gives rise to what $I$ have described elsewhere ${ }^{2}$ as a state of alkalipenia of varying degree. The intake of mineral salts may be insufficient for neutralising purposes, and the result is a relative acidosis, in which abnormal state the subject is more liable to be attacked by pathogenic organisms or to succumb easily to infection.

Thirdly. - The constant ingestion of excess of carbohydrates will tend to raise the level of blood sugar when there will be a more favourable opportunity for certain organisms to flourish and bring about a more or less chronic infection.

Summing up these three postulates, one may propound that a constant intake of excessive carbohydrate conjoined as it is with an upset of proper balance may produce a state of auto-intoxication, accompanied by a raised level of the blood sugar, together with some degree of alkalipenia, and in such a state of things there is resultant ill health manifested in various ways, as follows :-

\section{A.-Skin Conditions.}

(1) The Seborrhoic State. - I feel in agreement with Barber" who believes that " the chief underlying cause of this condition is faulty digestion and metabolism of carbohydrate, whereby an excess of organic acid by-products is produced, which are secreted through the sebaceous and sweat glands, causing an alteration in the composition of the sebum and sweat." He also suggests that there is presumably an alteration in the chemical composition of the epidermal cells which diminishes their resistance to bacterial infection, probably by affording the bacteria a more suitable medium for active growth." There is a moderate degree of alkalipenia in this condition brought about (a) by deficient intake of alkaline salts such as occur in fresh vegetables and fruit, and $(b)$ the using up of the body alkali reserve to neutralise the excess of acid by-products of incomplete combustion.

(2) Furunculosis. - Persistent and repeated crops of boils all over the body are commonly met with in some children which are difficult to cure.

The primary cause is undoubtedly metabolic, and the chemical composition of superficial cells among others is so altered that skin cocci can gain entrance and become established after producing sensitization. In these cases also the blood sugar is often raised, and a similar picture to that of Diabetes is presented, in which boils and carbuncles may occur as complications owing to the hyperglycaemia.

(3) Impetigo may be considered as an almost parallel condition, and our method of treatment by local application is successful because the type of lesion is more open and superficial, but it might 
perhaps be reinforced by a cutting down of carbohydrates and administration of alkalies.

(4) Blepharitis.--Two types of this common condition are generally met with in children:

(1) Squamous blepharitis, which is a form of seborrhœea and therefore can be considered under that heading.

(2) Ulcerative blepharitis in which yellow crusts are formed as a result of infection of the hair follicles.

In both these states, though they are usually associated with errors of refraction, there is an underlying debility brought about most probably by an unconsidered dyspepsia due to faulty diet.

(5) Hordoleum is only a name given to a boil occurring in a certain situation, and it can be cured by restriction of carbohydrates and by alkali therapy.

\section{B. CaRIES OF TEETH.}

No one can deny that the diet of modern civilisation is a very large factor in the production of caries. Lack of sufficient cleansing foods, and excess of soft glutinous substances which stick to the teeth and ferment with acid formation may be considered as one cause of enamel destruction. If also there is a degree of alkalipenia which may be induced by drawing on the body alkali reserve either for the neutralisation of excess metabolic acid bye-products, or the acid toxins of acute infections, the alkalinity of the saliva will be diminished, as has been shown experimentally ${ }^{4}$, and the combination of these two factors, i.e., hypoalkalinity of the saliva and acid fermentation products is sufficient to initiate caries.

\section{C.-Rickets.}

Insufficient sunlight, fresh air and exercise, avitaminosis, defective calcium metabolism, errors of diet and micro-organisms-these are some of the theories wholly or partly held to-day concerning this disease.

Without disputing any of them, I wish to draw particular attention to the diet side of the question. It is common knowledge that among infants and children, if the diet is an unbalanced one it is more than likely-nay, it is almost certain - that it will be one in which carbohydrates predominate and fats are deficient. Cory $\mathrm{Mann}^{5}$ with regard to the etiology of rickets concluded that " of "the conditions which predispose to the occurrence of rachitic deformities in children under the age of 2 years, the continual use of an unbalanced diet, characterized by deficiency of fat and excess of carbohydrate, will be found to have antedated the appearance of symptoms in about 45 per cent. of the total cases." All the common etiological factors of rickets lead to the defective oxidation of the food consumed and to the production of acids, and Barr ${ }^{6}$ has shown that excessive amounts of acids, whether taken by mouth or generated by the fermentation of carbohydrates in the stomach would extract the lime salts from the bones, cartilages, fibrous tissues and nerves ; and Hodgson ${ }^{7}$ by further experimental evidence deduced that a compensated acidosis or what I have termed alkalipenia, was present in active rickets, as demonstrated by a reduction of the alkaline reserve.

\section{D.-The Exudative Diathesis.}

Under this heading, I wish to include chronic gastro-intestinal catarrh, Pharyngitis, Enlarged Tonsils and Adenoids and certain cases of Bronchial Catarrh.

Among elementary school children one often comes across a child who is said to be wasting and has a cough. Too often is the case referred to the Tuberculosis Officer as a suspect case of Pulmonary Tuberculosis, whereas a more thorough examination of the patient, and a more detailed inquiry of the mother for symptoms would in many cases clinch the diagnosis of chronic intestinal indigestion.

This condition may be due to congenital inability to digest and assimilate a proper diet, but it is more often an acquired condition brought about by improper feeding in which excess of carbohydrates is a prominent factor. It is characterised by a catarrh of the intestinal tract, but the catarrh may occur in other regions of the body, at the same time. For example, there is often chronic pharyngitis, more or less enlargement of the tonsils, and very frequently adenoids. French authors say that such children have the "arthritic diathesis."

I notice that Sir George Newman ${ }^{8}$ states that the principal defect of the nose and throat in school children is that of enlarged tonsils and adenoids caused by a combination of factors, which include improper diet, intestinal indigestion, toxæmia and infection.

As an illustration of the curious sympathy which exists between the respiratory and alimentary tracts, I will describe the clinical picture of three cases that I observed and treated at a children's hospital some time ago.

Case C.G. : Girl, aged 7. A sister was in hospital a year ago with asthma. Been quite well lately. Got up in the morning with a pain in the chest. Vomited, but no cough. Admitted in evening; P. $150, T$. 98.4, R. 50. No cyanosis, but laboured breathing and a smeil of acetone. Lungs: Generalised bubbling rales. Abdomen nil 
abnormal. Tongue dry and slightly furred. Urine acid $t$, acetone $t+$, aceto-acetic acid ++ . She was given 80 grains of sodium bicarbonate immediately, and in two hours' time the hyperpnoea had disappeared. On alkaline treatment the acctone bodies departed after 3 days and the child made a perfect recovery.

Case N. H. : Girl, aged $4 \frac{1}{2}$. Grandmother suffers from asthma. Was sent to hospital as a case of bad bronchitis. Has had four similar attacks, one of which was diagnosed as Laryngeal Diphtheria, but the condition was not present. Attacks usually last about 10 days and consist of wheezing and laboured respiration. Has never vomited in her life. Quite well and running about day before admission, and at 9 p.m. became restless and breathing became bad. Not unconscious, but won't answer and won't eat. On first observation looks like a case of Laryngeal Diphtheria, with apparent obstructed breathing and rattling of mucus in throat, but no cyanosis. Lies as if in coma at times. P. 160, T. 98, R. 60. Lips and cheeks red. No smell of acetone in breath. Lungs, no dulness, moist rales and occasional expiratory rhonchi. Abdomen and heart, nil found. Urine by catheter acid $t+t$, acetone $t+t$, aceto-acetic acid ++ . Next day child still in semi-comatose state, but sits up at times and can be roused easily. Sodium bicarbonate given per rectum as well as by mouth. During evening became comatose and was given 80 grains of sodium bicarbonate by mouth and six ounces of 2 per cent. sod. bicarb. in saline subcutaneously.

The following day much better, chest less wheezy. Four days later the child was well and happy.

Case E. C.: Boy, aged $2 \frac{3}{4}$ years. Admitted for old infantile paralysis. Has had whoopingcough and eczema which lasted for one year. Normal on admission. The next day he became drowsy with increased respiration rate, red lips and cheeks, strong smell of acetone, and large amount in urine. The temperature was $100^{\circ}$ and there was generalised coarse rales in the chest.

He was given sod. bicarb. until the urine became alkaline and the amount ingested was 590 grains. He then sat up in bed and played with toys, though comatose the day before; the temperature dropped to normal on the fourth day and the lungs became absolutely normal and the urine free of acetone bodies. Marked constipation and oliguria were prominent features in the case.
The first two cases might be regarded as asthmatic seizures, but they were by no means typical, and I feel that these respiratory manifestations in children, connected as they are with alimentary disturbances, constitute a definite symptom complex of one form of ketosis. Instead of a constriction of bronchioles as in true asthma, there is an outpouring of mucus, and the therapeutic action of sodium bicarbonate in checking the mucus secretion, dissolving that already secreted, in neutralizing the acidity, and in transporting $\mathrm{CO}_{3}$ is well illustrated in the above cases.

In passing I should like to mention that I have found that Ketonuria, Alkalipenia, Leucopenia, and Eosinophilia are common factors in the following metabolic complaints: Asthma; Eczema, Urticaria, Migraine, Eclampsia and some forms of Epilepsy.

What was the cause of the sudden outbursts in the three cases mentioned above? Bacterial invasion does not seem likely; is it not probable that this catarrh was activated by some chemical agent of an acid nature, derived from food, and if correlated with the catarrhs already mentioned, can be ascribed to faulty carbohydrate netabolism?

In summing up these varied complaints, for which an unbalanced diet with excess of carbohydrates has been blamed, it is argued that there may arise a toxæmia of such a nature that the body alkali reserve is being constantly drained, and that the toxamia is produced by the circulation of some chemical irritant to which the tissues respond in some cases by pouring out protective mucus, and finally the whole tone of the body is so lowered that micro-organisms can play their part, with less resistance from their host than they would meet with in a healthy individual.

Undoubtedly very many children and adults exceed the recognised ration of carbohydrate and do not suffer, but it is to those whose tolerance has been broken down by the excess that this paper chiefly refers.

Among the poorer classes the problem of a suitably balanced diet is largely an economic one, among the rich it is a matter of lack of knowledge, but education can be applied to all alike, to the former especially at Infant Welfare Centres, and if the babies of the future are brought up from the beginning on right lines, their panel doctors in after life may not have so many of those tiresome cases to deal with, who describe in their own words their complaints such as "gastric stomach " or "rheumatics," 


\section{ReFERENCES.}

1. McCarrison, R. Brit. Med. Jour., July 12, 1919, p. 37.

2. The Lancet. April 1, 1922.

3. Barber, H. W. Brit. Med. Jour., Oct. 21, 1922, p. 755.

4. Broderick, F. W. Brit. Dent. Jour, Oct. 15, 1920.

5. Corry Mann, H. Medical Research Council Report. Series No. 68, p. 99.

6. Barr, Sir J. Discussion on Vitamines. B.M.A. Meeting, Cambridge, 1920.

7. Hodgson, A. Lancet, 1921, ii., p. 945.

8. Newman, Sir G. Annual Report to Board of Education, 1921. "The Health of the School Child," p. 55.

NOTES FROM BRANCHES.

1 NORTH WESTERN BRANCH.

\section{MILK PROSECUTYON.}

Two charges of selling milk containing added water were brought against Albert Garner, of Holly Cottage, Helsby, by the Cheshire County Council at the Frodsham Petty Sessions on May 16th.

Inspector Hallard stated that at 8.30 on the morning of April 23rd, he was at the Cheshire Creamery, Helsby, when the defendant brought a supply of milk there. Witness took a sample and the Public Analyst's certificate showed that the milk contained 20.7 per cent. of added water.

The defendant denied that the milk had been watered. "He stated that he had six cows which gave about 12 gallons of milk a day. He milked the cows on the evening of April 22nd, when the weather was cold, and in his opinion the weather had affected the quality of milk the cows gave. He had been feeding them on potatoes and cabbage and the grass they had had was not of very good quality, and he had noticed the falling off in the quality of the milk produced but he could not help that.

In his defence the Solicitor for the defendant stated that Mr. Garner had a clean record and drew attention to the circular No. 325 issued by the Ministry of Health last year, stating that if a person charged had a good record, and if any special circumstances existed to account for the milk being deficient, consideration should be given to these points. He submitted Mr. Garner had, beyond all doubt, been doing his best to supply good milk.

The second charge was of selling milk containing
11.2 per cent of added water. The sample was taken on the same day from a tankard in the defendant's cart outside the Creamery, which he was retailing.

The manager of the Creamery was called for ward to answer a question from the Bench as to whether the milk was sold by measure or by weight. He was also asked by the Chairman of the Bench if the defendant's milk received at the Creamery had been satisfactory before, whereupon the Solicitor for the defence asked for a dismissal of the case on the ground that a question had been asked of an unsworn witness before the Bench had heard the defence.

The Bench, after deliberation in private, dismissed both cases.

\section{THE SCOTTISH BRANCH.}

ENTERIC FEVER FROM MILK.

Arising out of the widespread epidemic of Enteric Fever in the Burgh of Campbeltown, an interesting decision has been given in the Sheriff's Court at that Burgh regarding the duty of the farmer in respect of the health of the milkers employed by him. The salient points in the case were as follows:-

One of the female workers had been feeling out of sorts for three days, but had continued her work. On the evening of the fourth day, the milker sent him a message that she was unable to carry on her duties, and provided a substitute. On the fifth day, however, the millser was able to resume work and completed the day's milking that day. On the following day, however, she was much worse, and was not employed on the farm again. Four days later it was discovered by the Medical Officer of Health that she had symptoms of Enteric Fever, which was corroborated two days later by examinations of the patient's blood.

It was proved, or admitted, in court that the patient was suffering from Enteric Fever, and the onset was probably twelve days before diagnosis was made. The farmer had no suspicion that the patient was suffering from Enteric Fever, but he allowed her to resume work, after having reported sick, without a medical certificate that she was not suffering from any infectious disease.

The proper thing for the farmer to have done when the patient sought to resume work was to request a certificate from her medical attendant that she did not suffer from an infectious disease, 